\title{
Influence of precipitation seasonality on glacier mass balance and its sensitivity to climate change
}

\author{
Koji FUJITA \\ Graduate School of Environmental Studies, Nagoya University, Nagoya 464-8601, Japan \\ E-mail: cozy@nagoya-u.jp
}

\begin{abstract}
Numerical calculations are described, aimed at evaluating the influence of precipitation seasonality (summer and winter) on glacier mass balance. First, equilibrium-line altitudes (ELAs) are modeled using idealized meteorological variables. Modeled climatic conditions (summer mean temperature and annual precipitation) at the ELA of glaciers located within a winter accumulation pattern confirm the observational results of earlier studies. However, the ELA of glaciers located within a summer accumulation climate pattern locates in a colder environment than that of glaciers located within a winter accumulation climate pattern. This difference is mainly due to the annual snow accumulation and the surface albedo. A warming test $(+1 \mathrm{~K})$ reveals higher sensitivities for the glaciers located within a summer accumulation pattern than for the glaciers located within a winter accumulation pattern. In a humid environment, a significant decrease in snow accumulation on the glaciers located within a summer accumulation pattern directly causes higher sensitivities. In an arid environment, on the other hand, the decreased summer snow induces accelerated melting by lowering the surface albedo and thus increasing absorption of solar radiation on the glaciers located within a summer accumulation pattern. Both influences are due to significant differences in summer precipitation. This study shows the importance of precipitation seasonality on the climatic sensitivity of glacier mass balance, which in previous studies has been linked only with annual precipitation.
\end{abstract}

\section{INTRODUCTION}

Despite the relatively small amounts of ice stored as nonpolar glaciers against the total amount of land ice on earth, these glaciers are thought to have had a significant effect on sea-level rise during the last century, since they have higher mass-balance sensitivity than the large ice sheets of Greenland and Antarctica. Using glacier mass-balance data, Meier (1984) estimated about half of the sea-level rise was attributable to the shrinkage of non-polar glaciers. Meier's approach was based on the assumption that the thinning rate of glaciers was proportional to the annual balance amplitude, which is approximately equivalent to the annual precipitation on the glaciers. It is necessary to extrapolate the scarce mass-balance measurements to large areas and to the century timescale. Later studies summarized the climatic sensitivity of glacier mass balance (how much mass will be wasted against $+1 \mathrm{~K}$ warming) as a function of the annual precipitation on individual glaciers, and confirmed Meier's idea (e.g. Oerlemans and Fortuin, 1992; Braithwaite and Raper, 2002; Raper and Braithwaite, 2006).

Despite the efforts made in subsequent studies to obtain more precise estimates based on the observational data (Dyurgerov and Meier, 1997a, b; Cogley and Adams, 1998), major uncertainties still remain due to the serious lack of measurement data for the Asian region. Since the region includes an extensive glacier area $\left(119 \times 103 \mathrm{~km}^{2}, 18 \%\right.$ of the total area of non-polar glaciers (Dyurgerov and Meier, 1997b)), any uncertainty will generate considerable estimation errors. In addition, previous numerical studies have applied their models, mainly validated with glaciers in Europe and the Americas, to glaciers worldwide (Oerlemans and Fortuin, 1992; Braithwaite and Raper, 2002; Raper and Braithwaite, 2006). A few studies using a numerical approach, on the other hand, have suggested higher glacier mass-balance climatic sensitivity in the Asian highlands (Ageta and Higuchi, 1984; Fujita and Ageta, 2000), though their calculations were performed on specific glaciers in the Himalaya and Tibet. They concluded that snowfall during summer could, with warming, fall as rain, and the decrease in fresh snow would then reduce the glacier surface albedo, leading to greater ablation from the glacier. Because many glaciers are located within a summer accumulation climate pattern, not only in Asia but also in other regions such as South America, it is meaningful to evaluate the effect of precipitation seasonality on glacier mass balance and its climatic sensitivity. Calculations are performed here using a heat-balance model with a simple meteorological pattern to describe the influence of precipitation seasonality on the features and climatic sensitivity of the glacier mass balance.

\section{MASS-BALANCE MODEL AND SIMPLE CLIMATE VARIABLES}

The energy-/mass-balance model used in the study calculates the daily heat balance at the glacier surface, including radiation balance, sensible and latent turbulent heat fluxes, heat conduction into the glacier, and mass balance consisting of snow accumulation, melt, refreezing and evaporation:

$\left[Q_{\mathrm{M}}, 0\right]=(1-\alpha) R_{\mathrm{S}}+R_{\mathrm{L}}-\left[315.6, \sigma T_{\mathrm{S}}^{4}\right]+Q_{\mathrm{S}}+E_{\mathrm{V}} l_{\mathrm{e}}+Q_{\mathrm{G}}$.

Heat for melting $\left(Q_{M}\right)$ is obtained if the righthand side of the equation is larger than zero. Absorbed shortwave radiation is calculated from surface albedo $(\alpha)$ and downward shortwave radiation $\left(R_{\mathrm{S}}\right)$. Downward longwave radiation $\left(R_{\mathrm{L}}\right)$ is calculated from air temperature, relative humidity and the ratio of downward shortwave radiation to that at the top of the atmosphere using an empirical scheme (Kondo, 1994). 
Upward longwave radiation is obtained by the StefanBoltzmann constant $(\sigma)$ and surface temperature in Kelvin $\left(T_{\mathrm{S}}\right)$ assuming black body for the snow/ice surface. A melting surface $\left(0^{\circ} \mathrm{C}\right.$ surface temperature) releases an upward longwave radiation of $315.6 \mathrm{~W} \mathrm{~m}^{-2}$. Sensible $\left(Q_{\mathrm{S}}\right)$ and latent $\left(E_{\mathrm{V}} l_{\mathrm{e}}\right)$ turbulent heat fluxes are obtained by bulk methods. $l_{\mathrm{e}}$ is the latent heat for evaporation of water or ice, which is determined from the surface temperature. Conductive heat into the glacier ice $\left(Q_{\mathrm{G}}\right)$ is obtained by calculating the temperature profile of the snow layer and/or glacier ice. Absorption of shortwave radiation in snow and ice, which increases the temperature of the snow and ice, is taken into account (Fujita and Ageta, 2000). All heat components are positive when fluxes are directed toward the surface. Mass balance $(B)$ at any location on the glacier is calculated as

$$
B=\mathrm{Ca}-\frac{Q_{\mathrm{M}}}{I_{\mathrm{m}}}+E_{\mathrm{V}}+R_{\mathrm{F}}
$$

Solid precipitation ( $\mathrm{Ca}$, positive sign), which is determined along with air temperature, is equivalent to accumulation over the glacier. Mass is removed from the glacier as meltwater $\left(Q_{\mathrm{M}} / I_{\mathrm{m}}\right.$, positive sign) and evaporation ( $E_{\mathrm{V}}$, negative sign). $I_{\mathrm{m}}$ is the latent heat for melting ice. A part of the meltwater is fixed to the glacier by refreezing $\left(R_{\mathrm{F}}\right.$, positive sign) if the glacier ice is cold enough (Fujita and others, 1996). The refreezing amount is calculated in the model by considering the conductive heat into glacier ice and the presence of water at the interface between the snow layer and glacier ice (Fujita and Ageta, 2000). Refreezing during winter and shorter cooling events are also calculated. Special attention should be paid to treatment of the surface albedo $(\alpha)$, as it varies enormously in space and time even on a single glacier (albedo declines down a glacier and during the course of the melt season). The albedo in the model was calculated according to the surface snow density, which changes with snow compaction. This treatment guarantees the feedback effect of albedo in climatic change experiments. Validation of the model was performed for a Tibetan glacier, considering parameters such as ice temperature, seasonal change in levels of surface snow (accumulation and ablation) and ice (meltwater refreezing), albedo at different altitudes, and altitudinal profile of mass balance (Fujita and Ageta, 2000). Detailed schemes have been described by Fujita and Ageta (2000) for the entire model and by Fujita (2007) for albedo and snow densification.

Since our purpose is not to examine specific glaciers, but to evaluate the influence of the main precipitation seasons on glacier mass balance, we set up an ideal meteorological input as shown in Figure 1. Air temperature (Fig. 1a) and solar radiation (Fig. 1d) have clear seasonality assuming the Northern Hemisphere. Two precipitation patterns (Fig. 1b), which are the main concern of this calculation, are set by setting their peaks with the coldest date at the end of January (winter precipitation pattern) and the hottest date in early August (summer precipitation pattern). Multiplying the precipitation ratio by the annual precipitation gives the amount of daily precipitation. Other meteorological variables are set as simple periodic patterns (Fig. 1c). Solar radiation at the glacier is obtained by multiplying transmissivity (Fig. 1c) and solar radiation at the top of the atmosphere (Fig. 1d). All variables have a weekly periodic pattern suggesting a mesoscale atmospheric circulation. Because a combination of weekly peaks of precipitation and air temperature significantly affects the calculated results,
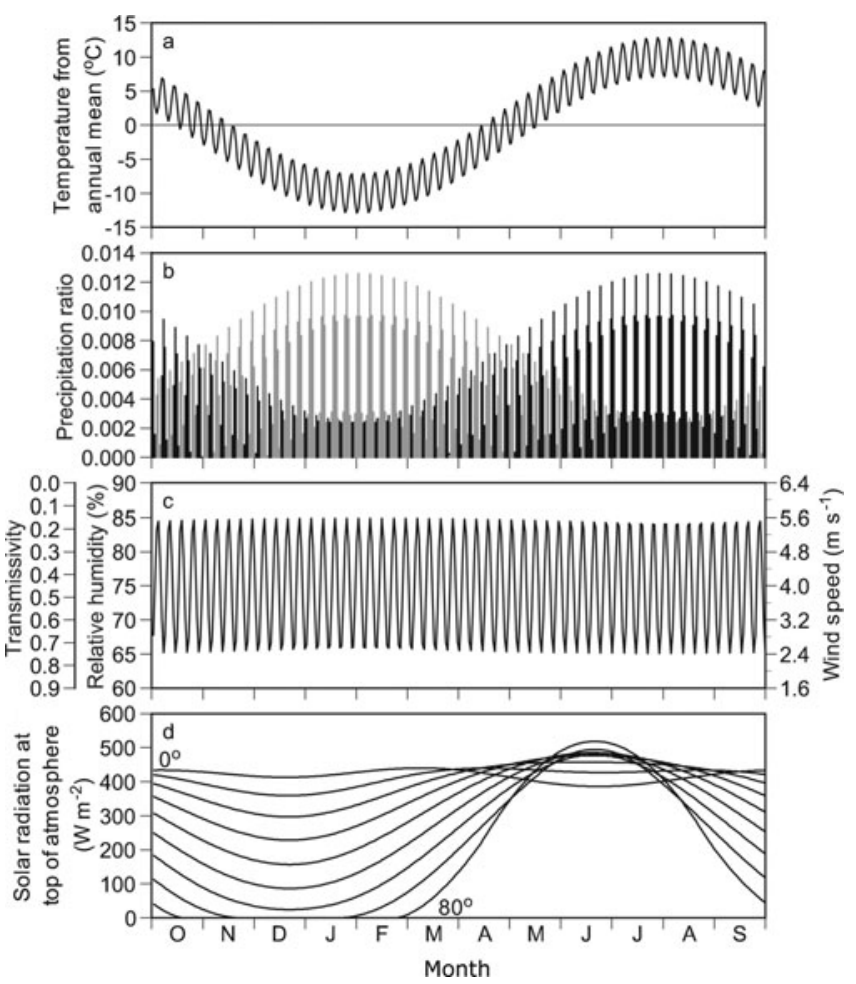

Fig. 1. Simplified meteorological variables for the model: (a) air temperature; (b) two patterns of precipitation ratio, summer (black bars) and winter (grey bars); (c) wind speed, relative humidity and transmissivity for solar radiation, expressed by a single curve with different ordinate axes; and (d) solar radiation at the top of the atmosphere. Multiplying the precipitation ratio by the annual precipitation gives the daily precipitation. Multiplying solar radiation at the top of the atmosphere, which is obtained at each latitude, by the transmissivity gives the solar radiation at the surface.

the seasonal peak of precipitation is changed \pm 3 days from the primary settings, so the 7 day averages of output are discussed hereafter. Weekly patterns of relative humidity and transmissivity are also changed consistently with that of precipitation (e.g. high humidity and low transmissivity with precipitation peak, and the converse).

\section{CLIMATIC AND SURFACE CONDITIONS AT ELA}

First, we calculate the equilibrium-line altitude (ELA; altitude where annual accumulation and ablation are equal) by changing air temperature $\left(0.3^{\circ} \mathrm{C}\right.$ step), annual precipitation ( $0.2 \mathrm{~m}$ w.e. step) and latitude $\left(10^{\circ} \mathrm{step}\right)$. The annual cycle starts in October. Calculated results of the fifth year are obtained for the stabilization of glacier ice temperature. Second, air temperature is everywhere increased by $+1 \mathrm{~K}$ in the sixth year, and the mass balance at the original ELA is obtained as a measure of climatic sensitivity. Much fine tuning has had to be done in previous studies to obtain specific mass balances (averaged for the whole glacier area) (e.g. Oerlemans and Fortuin, 1992; Gregory and Oerlemans, 1998; Braithwaite and Raper, 2002; Raper and Braithwaite, 2006). Any change in the altitudinal distribution of precipitation, for instance, will seriously alter the glacier mass balance (Oerlemans and Fortuin, 1992). Spatial distributions and fluctuations in meteorological variables within a certain region, however, are not fully understood worldwide. On the other hand, conditions at the ELA are close to the 


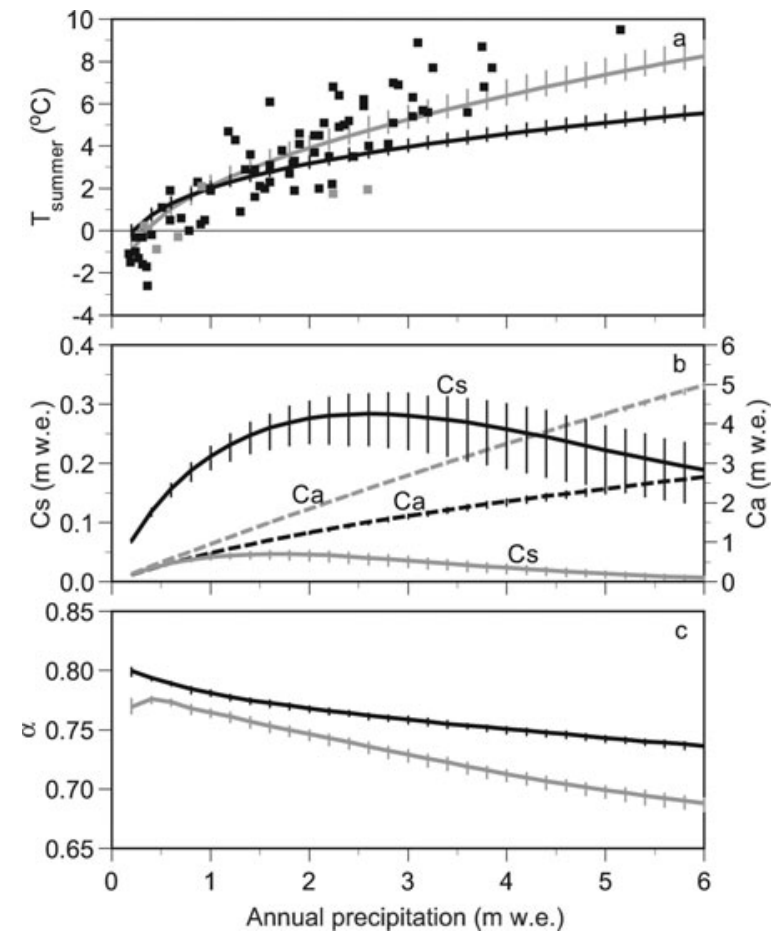

Fig. 2. (a) Summer air temperature ( $\left.T_{\text {summer }}\right)$ plotted against annual precipitation at the ELA. Black squares are observational relationships cited from Ohmura and others (1992). Grey squares are data updated here, for glaciers under the Asian summer monsoon. (b) Annual (Ca; dashed curves) and summer (June-August) (Cs; solid curves) accumulation at the summer-type glacier (black curves) and winter-type glacier (grey curves) at the ELAs. (c) Annual mean surface albedo at the ELAs. Error bars are the range between maximum and minimum derived at different latitudes.

average for the whole glacier. Thus, the conditions and climatic sensitivity to warming of the ELA are dealt with as indices of glacier mass balance in this study.

Figure 2a shows the relationship between annual precipitation and summer mean air temperature at the ELA $\left(T_{\text {summer }}\right) . T_{\text {summer }}$ is calculated for glaciers located within a summer accumulation climate pattern (summer-type glaciers) and for glaciers located within a winter accumulation climate pattern (winter-type glaciers). Calculations are for observed glaciers worldwide (Ohmura and others, 1992), including the updated data for Himalayan glaciers (Fujita and others, 1998, 2000, 2001a, b; unpublished data). Under a humid environment (annual precipitation $>1 \mathrm{~m}$ w.e.), the ELAs of winter-type glaciers will be located in warmer conditions than those of summer-type glaciers (Fig. 2a). A higher amount of annual precipitation on the winter-type glaciers simply increases annual accumulation (Ca in Fig. 2b). It allows the ELA to locate at a lower elevation because more snow melts at higher temperatures in the melting season. On summer-type glaciers, however, an increase of annual precipitation does not cause greater snow accumulation because the significantly warmer environment changes precipitation from snowfall to rainfall. Because rain does not contribute to glacier mass gain (Fig. 2b), the ELA of a summer-type glacier does not locate at a lower elevation compared to that of a winter-type glacier. The difference in summer mean temperatures between summer- and wintertype glaciers is explained in terms of the annual accumulation. Figure 3, in which summer mean temperatures are

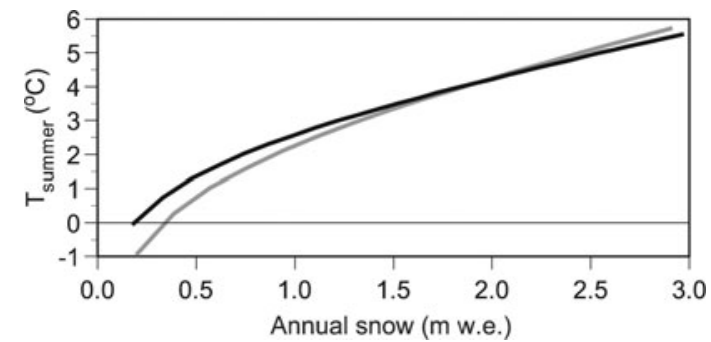

Fig. 3. Summer air temperature plotted against annual snow at the ELA. Black and grey lines denote summer- and winter-type glaciers, respectively.

related to annual snow accumulation, implies no significant difference between summer- and winter-type glaciers in a humid environment. Under a lower-precipitation environment, on the other hand (annual precipitation $<1$ mw.e.), the ELA of summer-type glaciers can be located under warmer conditions than that of winter-type glaciers (Figs 2a and 3). Annual snow accumulation $(\mathrm{Ca})$ is always higher on the winter-type glaciers, while summer accumulation (Cs, summed during June-August) is significantly higher on summer-type glaciers (Fig. 2b). Higher summer accumulation makes for a higher annual mean surface albedo on the summer-type than on the winter-type glaciers (Fig. 2c). This suggests that snow cover during the melt season will suppress the absorption of solar radiation and melt, whereas the surface snow on winter-type glaciers will melt continuously throughout the summer without fresh snow cover.

\section{SENSITIVITIES OF MASS BALANCE TO WARMING}

To evaluate how the precipitation seasonality affects the sensitivity of glacier balance, a warming test $(+1 \mathrm{~K})$ was performed in the manner of Oerlemans and Fortuin (1992). The sensitivities for both summer- and winter-type glaciers increase with the annual amount of precipitation as Oerlemans and Fortuin (1992) indicated (Fig. 4a), though the sensitivities at the ELA (this study) and for the whole glacier (Oerlemans and Fortuin, 1992) are not simply comparable. The figure shows that summer-type glaciers have a notably higher sensitivity to warming than winter-type glaciers. Warming on the winter-type glaciers only prolongs the melting period without changing snowfall in summer (Fig. 4b), so that the decreases in surface albedo are only associated with a longer melting period (Fig. 4c). On the other hand, warming on the summer-type glaciers not only prolongs the melting period, but also causes a significant decrease in snow accumulation and an additional decrease in surface albedo due to a diminished summer snowfall that prevents the absorption of solar radiation and snowmelt during the melt season (Fig. $2 \mathrm{~b}$ and c). In order to evaluate their effects, a contribution ratio is calculated as

$$
\mathrm{Rc}=\frac{\left(\Delta \mathrm{Ca}_{\mathrm{sum}}-\Delta \mathrm{Ca}_{\mathrm{win}}\right)}{\left(\Delta B_{\mathrm{sum}}-\Delta B_{\mathrm{win}}\right)} .
$$

This is the contribution ratio (Rc) of the difference of changes in annual accumulation ( $\triangle \mathrm{Ca}$ ) to the difference of changes in climatic sensitivity $(\Delta B)$ between summer ('sum') and winter ('win') glacier types. The Rc increases with annual precipitation (Fig. 4b) and implies that the difference in climatic sensitivities between summer- and winter-type glaciers shown in Figure 4a can be explained by the 


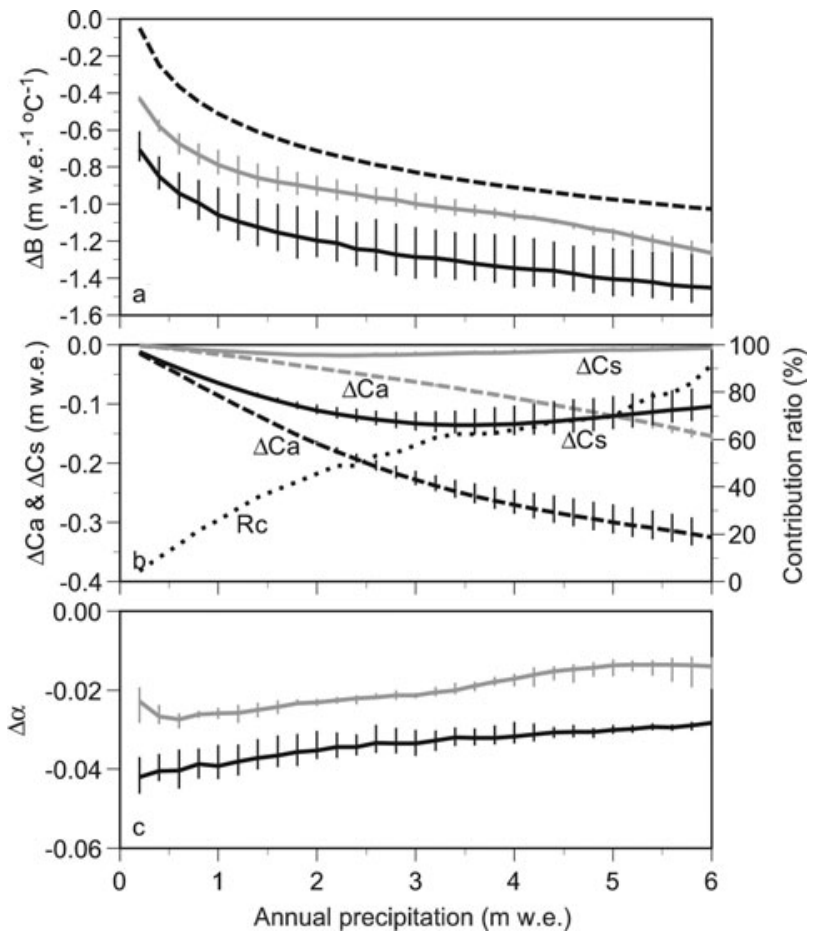

Fig. 4. Sensitivity to a uniform air-temperature increase $(+1 \mathrm{~K})$ of (a) annual mass balance $(\Delta B)$ at the ELA; (b) annual $(\Delta \mathrm{Ca}$; dashed curves) and summer ( $\Delta$ Cs; solid curves) snowfall; and (c) annual mean surface albedo. Black and grey curves denote summer- and winter-type glaciers respectively. Error bars are the range between maximum and minimum derived at different latitudes. Dashed line in (a) denotes the sensitivity from Oerlemans and Fortuin (1992). Dotted line in (b) indicates the contribution ratio of the difference of decreased annual accumulations to the difference of sensitivities between summer- and winter-type glaciers.

difference in decreased annual accumulation in the humid environment (Fig. 4b). Conversely, in the arid environment with little precipitation, the small Rc cannot be explained by the difference in decreased snowfall, and most of the difference will be due to the differences in melting.

Net balances of each heat component when melting occurs are summed, and their changes with $+1 \mathrm{~K}$ warming are shown in Figure 5. With a systematic difference in albedo shown in Figure 4c, changes in net shortwave radiation (dSR) in summer-type glaciers are significantly higher than those in winter-type glaciers (Fig. 5a). However, changes in the other net components such as longwave radiation $(\mathrm{dLR})$, sensible $(\mathrm{dSH})$ and latent $(\mathrm{dLH})$ turbulent heat fluxes are slightly larger in winter- than in summer-type glaciers. The warmer conditions at the ELA of winter-type glaciers in the humid environment not only cause more melt by warming but also prolong the melting period. Because the summation of these components results in heat for melting $(\mathrm{d} M \mathrm{H})$, the difference in net shortwave radiation change is compensated by the differences of the other heat components such as longwave radiation, and sensible and latent heat in a humid environment. In an arid environment, by contrast, the small differences in temperature conditions between summer- and winter-type glaciers cause insignificant differences in the heat components related to air temperature. A lowering of the albedo along with a significant decrease in snowfall in summer-type glaciers would therefore directly accelerate the absorption of solar

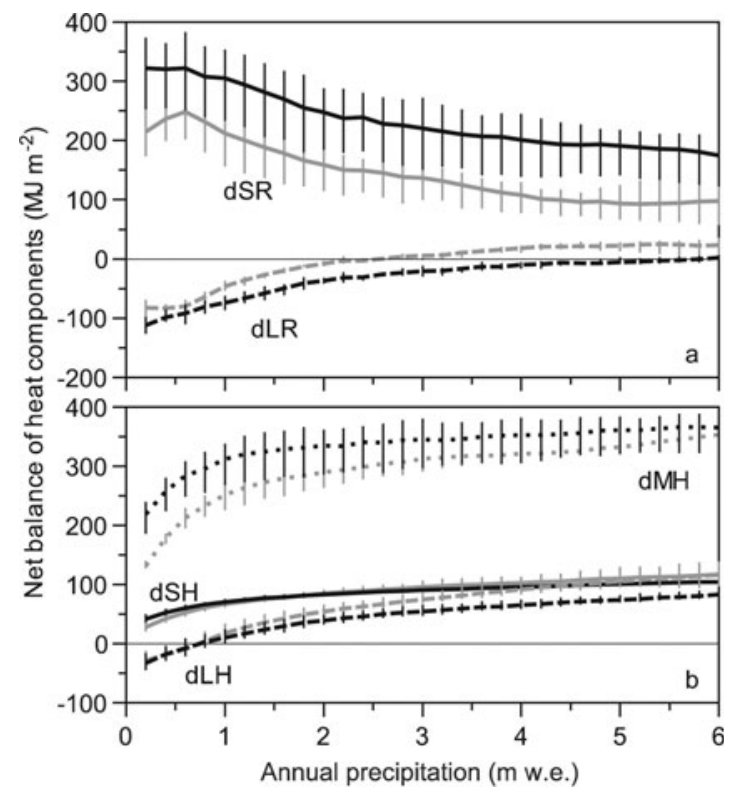

Fig. 5. Changes in net heat components associated with $\mathrm{a}+1 \mathrm{~K}$ warming. Each heat component is summed when the heat for melting is more than zero. (a) dSR (solid curves) and dLR (broken curves) denote short- and longwave radiations respectively. (b) dSH (solid curves), dLH (dashed curves) and dMH (dotted curves) denote sensible and latent turbulent heat fluxes, and heat for melting, respectively. Black and grey curves denote summer- and wintertype glaciers respectively. Error bars are the range between maximum and minimum derived at different latitudes.

radiation and thus the melting. High sensitivity modeled for the summer-type glaciers therefore explains the rapid shrinkages observed in some Himalayan glaciers under the summer monsoon climate (Fujita and others, 1997, 2001b).

\section{CONCLUSIONS}

The climatic sensitivities of glacier mass balance were correlated only with annual precipitation in the previous studies by Oerlemans and Fortuin (1992) and Raper and Braithwaite (2006). Those authors validated their approaches by examining real glaciers worldwide in which both summer- and winter-type glaciers might be included. However, the precipitation seasonality has never been discussed in previous studies. For instance, Oerlemans (1992) used a constant precipitation through a year to obtain climatic sensitivities of glacier mass balance in Norway. This study shows that the precipitation seasonality significantly affects the climatic sensitivities of glacier mass balance. Significant differences in climatic sensitivities between summer- and winter-type glaciers were derived from the difference in decreased annual accumulation by warming in a humid environment. In an arid environment, by contrast, the difference in surface albedo due to decreased summer snow caused a difference between summer- and winter-type glaciers. Both were caused by the presence/absence of summer precipitation. This implies that the increased sensitivities with annual precipitation shown in previous studies are demonstrated. Climatic sensitivities derived from annual precipitation without considering precipitation seasonality might have caused significant uncertainty in discussion of the effect of 'global' warming on glaciers worldwide. 


\section{ACKNOWLEDGEMENTS}

I thank Y. Ageta for helpful remarks on the first draft of this paper, and R. Braithwaite and an anonymous reviewer for helpful comments. The research was supported by a Grantin-Aid for Scientific Research (No. 19253001) from the Ministry of Education, Culture, Sports, Science and Technology of Japan.

\section{REFERENCES}

Ageta, Y. and K. Higuchi. 1984. Estimation of mass balance components of a summer-accumulation type glacier in the Nepal Himalaya. Geogr. Ann., 66A(3), 249-255.

Braithwaite, R.J. and S.C.B. Raper. 2002. Glaciers and their contribution to sea level change. Phys. Chem. Earth, 27(3234), 1445-1454.

Cogley, J.G. and W.P. Adams. 1998. Mass balance of glaciers other than the ice sheets. J. Glaciol., 44(147), 315-325.

Dyurgerov, M.B. and M.F. Meier. 1997a. Mass balance of mountain and subpolar glaciers: a new global assessment for 1961-1990. Arct. Alp. Res., 29(4), 379-391.

Dyurgerov, M.B. and M.F. Meier. 1997b. Year-to-year fluctuations of global mass balance of small glaciers and their contribution to sea-level changes. Arct. Alp. Res., 29(4), 392-402.

Fujita, K. 2007. Effect of dust event timing on glacier runoff: sensitivity analysis for a Tibetan glacier. Hydrol. Process., 21(21), 2892-2896.

Fujita, K. and Y. Ageta. 2000. Effect of summer accumulation on glacier mass balance on the Tibetan Plateau revealed by massbalance model. J. Glaciol., 46(153), 244-252.

Fujita, K., K. Seko, Y. Ageta, P. Jianchen and Y. Tandong. 1996. Superimposed ice in glacier mass balance on the Tibetan Plateau. J. Glaciol., 42(142), 454-460.
Fujita, K., M. Nakawo, Y. Fujii and P. Paudyal. 1997. Change in glaciers in Hidden Valley, Mukut Himal, Nepal Himalayas, from 1974 to 1994. J. Glaciol., 43(145), 583-588.

Fujita, K., N. Takeuchi and K. Seko. 1998. Glaciological observations of Yala Glacier in Langtang Valley, Nepal Himalayas, 1994 and 1996. Bull. Glacier Res. 16, 75-81.

Fujita, K., Y. Ageta, P. Jianchen and Y. Tandong. 2000. Mass balance of Xiao Dongkemadi glacier on the central Tibetan Plateau from 1989 to 1995. Ann. Glaciol., 31, 159-163.

Fujita, K., F. Nakazawa and B. Rana. 2001a. Glaciological observations on Rikha Samba Glacier in Hidden Valley, Nepal Himalayas, 1998 and 1999. Bull. Glaciol. Res. 18, 31-35.

Fujita, K., T. Kadota, B. Rana, R.B. Kayastha and Y. Ageta. $2001 \mathrm{~b}$. Shrinkage of Glacier AX010 in Shorong region, Nepal Himalayas in the 1990s. Bull. Glaciol. Res. 18, 51-54.

Gregory, J.M. and J. Oerlemans. 1998. Simulated future sea-level rise due to glacier melt based on regionally and seasonally resolved temperature changes. Nature, 391(6666), 474-476.

Kondo, J. 1994. [Meteorology of water environment.] Tokyo, Asakura. [In Japanese.]

Meier, M.F. 1984. Contribution of small glaciers to global sea level. Science, 226(4681), 1418-1421.

Oerlemans, J. 1992. Climate sensitivity of glaciers in southern Norway: application of an energy-balance model to Nigardsbreen, Hellstugubreen and Alfotbreen. J. Glaciol., 38(129), 223-232.

Oerlemans, J. and J.P.F. Fortuin. 1992. Sensitivity of glaciers and small ice caps to greenhouse warming. Science, 258(5079), $115-117$.

Ohmura, A., P. Kasser and M. Funk. 1992. Climate at the equilibrium line of glaciers. J. Glaciol., 38(130), 397-411.

Raper, S.C.B. and R.J. Braithwaite. 2006. Low sea level rise projections from mountain glaciers and icecaps under global warming. Nature, 439(7074), 311-313. 